\title{
Early and Late Brain Toxicity after Prophylactic and Curative Whole-Brain Radiotherapy with or without Re-irradiation
}

\author{
Lena Marinova $^{1 *}$, Radoslav Georgiev ${ }^{2}$ and Nikolay Evgeniev ${ }^{3}$ \\ ${ }^{1}$ Department of Radiotherapy, Complex Oncology Center, Ruse, Bulgaria \\ 2Department of Imaging, Radiation therapy and Nuclear medicine, UMHAT"St. Marina", Varna, Bulgaria \\ ${ }^{3}$ Department of Medical oncology, Complex Oncology Center, Ruse, Bulgaria
}

*Corresponding author: Lena Marinova, Department of Radiotherapy, Complex Oncology Center, Russe, Bulgaria.

To Cite This Article: Lena Marinova, Radoslav Georgiev, Nikolay Evgeniev. Early and Late Brain Toxicity after Prophylactic and Curative WholeBrain Radiotherapy with or without Re-irradiation. Am J Biomed Sci \& Res. 2021 - 12(6). AJBSR.MS.ID.001807.

DOI: 10.34297/AJBSR.2021.12.001807.

Received: 眥 May 26, 2021; Published: 㘹 May 14, 2021

\begin{abstract}
Brain metastases (BM) are the most frequent intracranial neoplasms in adults. Due to the development of the imaging diagnosis and the efficacy of complex oncology treatment, there is a significantly increased overall survival of patients with malignancies. On this background, clinical cases with brain metastases are also with increasing frequency. In addition to surgery, their treatment involves the application of various radiotherapeutic techniques with different radiation volumes and fractionation of the radiation dose. We present four clinical cases with early and late neurotoxicity after radiotherapy (RT) on the prevention or treatment of brain recurrences or metastases.
\end{abstract}

The prophylactic whole-brain radiotherapy (WBRT) is a standard approach in the limited or advanced stage of small cell lung cancer (SCLC). In multiple brain metastases, radiotherapy is a major healing method, involving a self- WBRT, a WBRT with a boost in solitary brain metastasis or radio surgery of 1-4 metastases followed by a WBRT.

The purpose of this article is to define preventive measures in defining and planning different radiotherapeutic approaches in order to minimize early and late brain toxicity.

Keywords: Brain metastases; Prophylactic whole-brain radiotherapy; Whole-brain radiotherapy; Radio surgery; Early and late brain toxicity

\section{Introduction}

Brain metastases (BM) are the most frequent (between 10-15\%) intracranial neoplasms in adult patients [1]. BM may spread from any primary site, most common in lung, breast and gastrointestinal neoplasms [2]. BMs represents a significant health problem as it is believed that $20 \%$ to $40 \%$ of cancer people will develop metastatic cancer in the brain during their illness [3]. The incidence of BM is increasing as a result of the growing elderly population, advances in detection with imaging techniques, and (systemic) cancer treatments that prolong life and allow BM to develop [4-6]. Most trials focusing on brain metastasis patients evaluated the efficacy of various treatment options through common endpoints such as survival, imagistic response rate, neurologic status or time to intracerebral recurrence [7-9]. In this article, we present four clinical cases with early and late neurotoxicity after radiotherapy (RT) on the prevention or treatment of brain recurrences or metastases. We will try to identify preventive measures in RT planning in order to minimize these early and late side effects brain radiotherapy.

\section{Clinical Cases}

\section{First clinical case}

A 73-year-old patient after fibrobronchoscopy (FBS) with histologically and immunohistochemically (IHC) proven small cell lung cancer (SCLC) (T4 N1 M1/pleural) was presented. First-line chemotherapy $(\mathrm{Ch})$ (Cisplatin and Etoposide) were performed. 
CT of the lung after 6 cycles of $\mathrm{Ch}$ - Tumor lesion of the right lobe bronchus with infiltration of the pleura - without dynamics. No secondary changes are reported bilaterally. Mediastinum - without enlarged lymph nodes bilaterally. A small discrete effusion in the right pleura was reported. CT of the brain - No secondary changes in the brain parenchyma. Ventricular system - unexpanded (Figure 1).
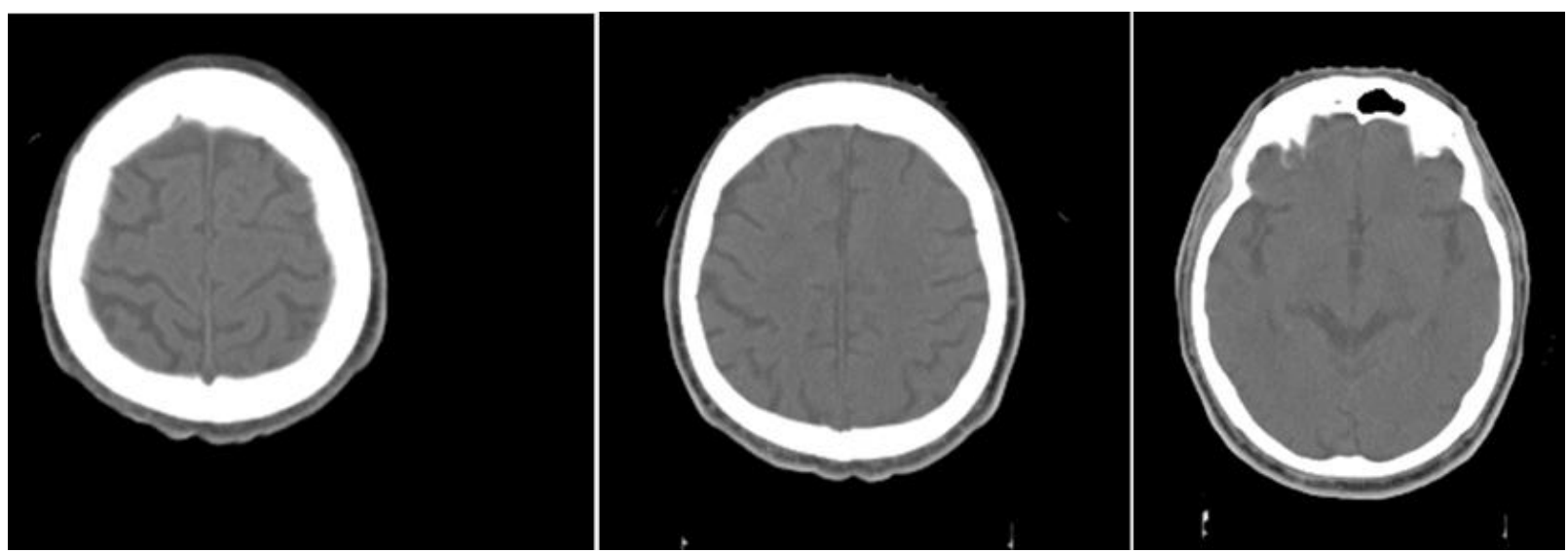

Figure 1: CT of the brain without pathological changes.

Intensity-modulated prophylactic whole-brain radiotherapy (WBRT) with daily dose (DD) 3 Gy up to total dose (TD) $30 \mathrm{~Gy} /$ Biologically equivalent dose (BED) $38 \mathrm{~Gy} / 5$ times per week was performed (Figure 2).

Three months after WBRT, the patient complained of difficulty in balance and weakness of the right limbs. CT of brain with venous contrast - Parenchymal brain pathology is not visualized subtentorially. Edema zones temporoparietally and occipitally in the left cerebellar hemisphere, without visible nuclei of metastases are reported. Ventricular system and basal cisterns - undilated, without dislocation. Mild cortical atrophy bilaterally temporally is visualized (Figure 3).
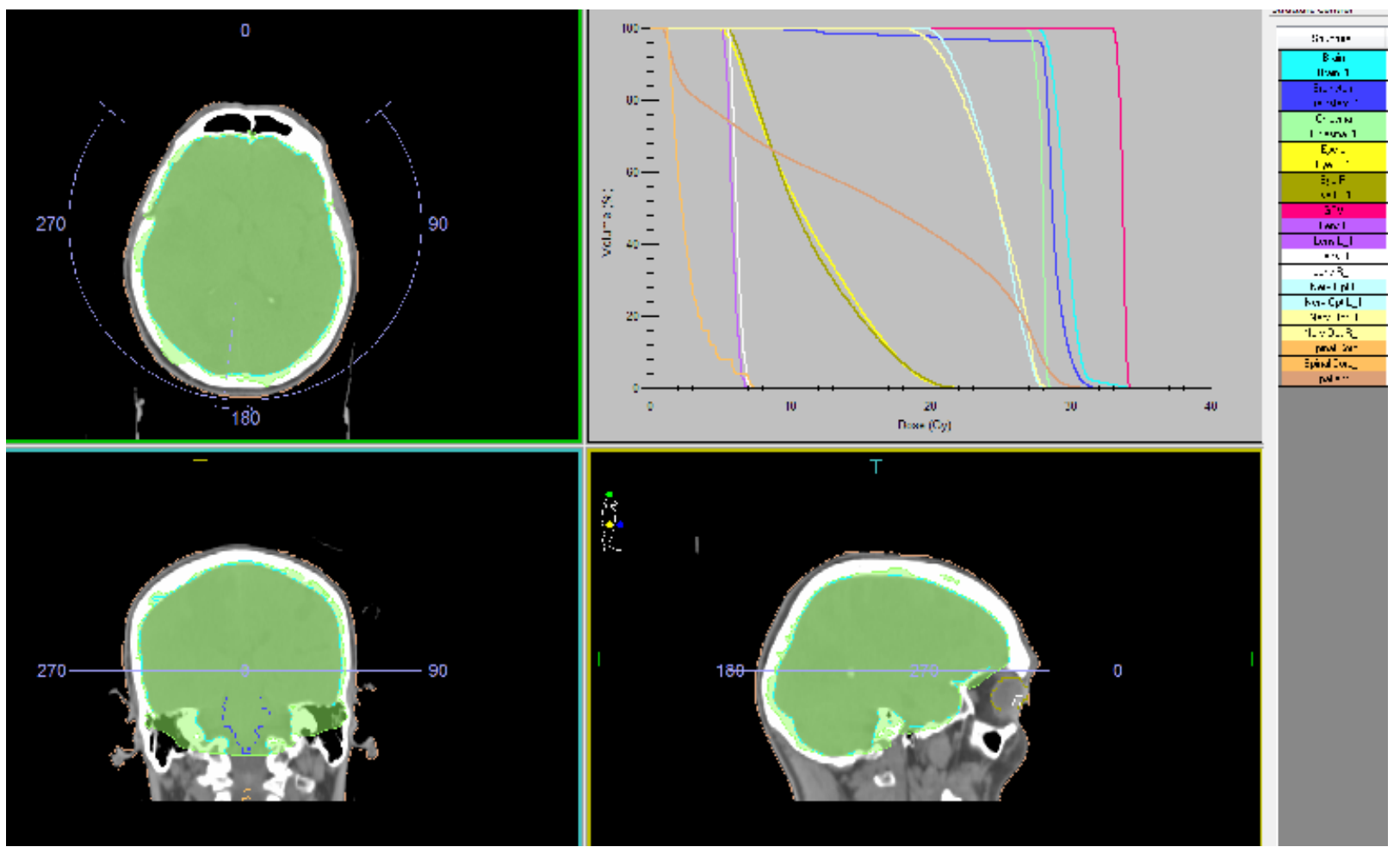

Figure 2: The Intensity modulated prophylactic whole-brain radiotherapy (WBRT) with daily dose (DD) 3 Gy up to total dose (TD) 30 Gy. 


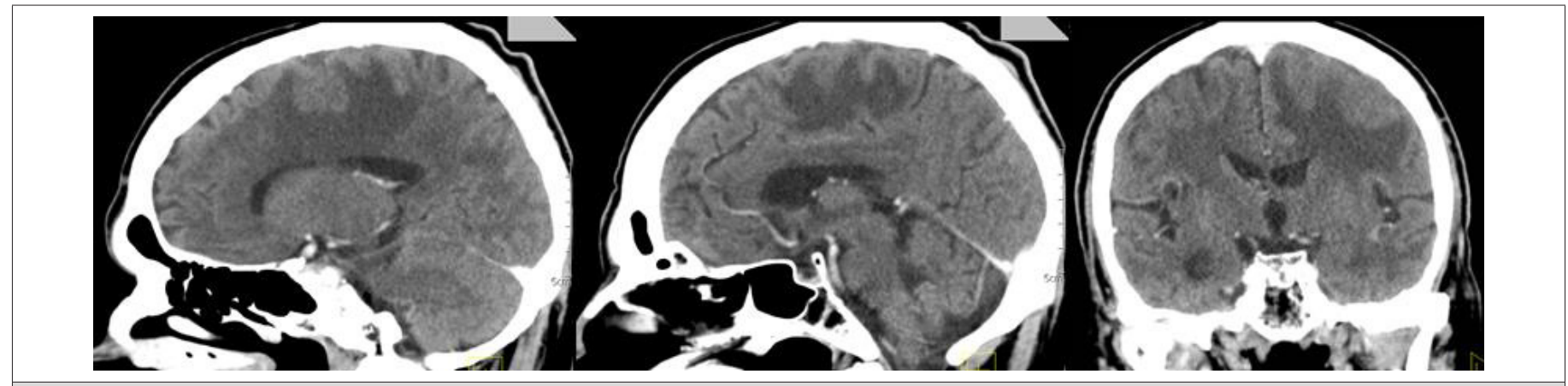

Figure 3: CT of the brain after 3 months of prophylactic WBRT - Edematous areas temporoparietally and occipitally in the left cerebral hemisphere.

MRI of the brain (Figure 4) - Against the background of advanced changes in chronic ischemic disease of the small vessels, in the left parietal extensive cerebral edema, mild compression of the body of the left lateral ventricle. Post-contrast scans lack pathological capture of the contrast material. Infratentorial without evidence of pathological lesions. Conclusion - The MR finding corresponds to subacute changes after RT, without data on the presence of radionecrosis and without data on metastases. The patient was hospitalized with a worsened general condition and complained of fatigue, dizziness, hemiparesis of the right limbs and central involvement of the right facial nerve. Despite anti-edema and antiinflammatory therapy, the patient exits after 18 days.

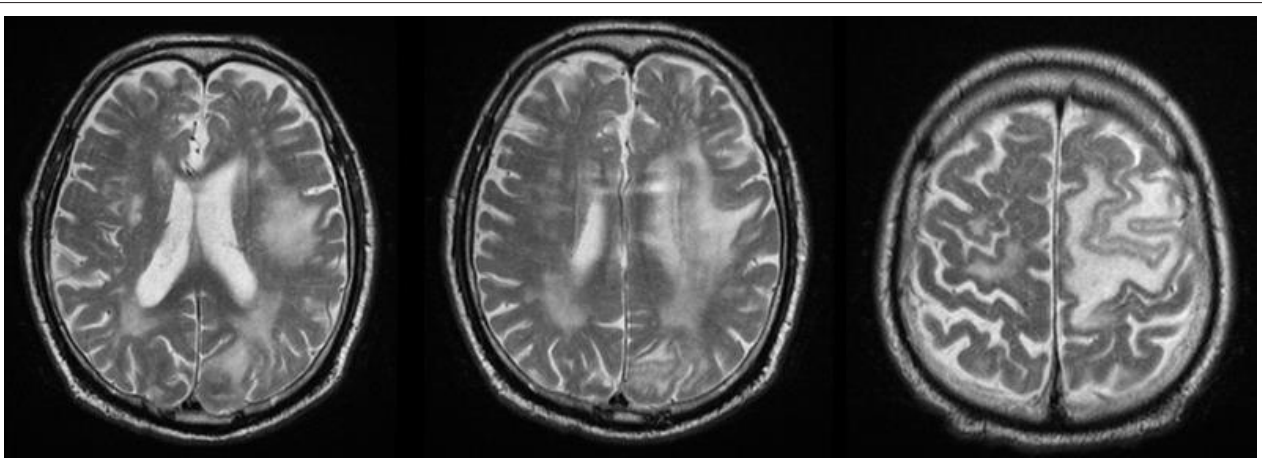

Figure 4: MRI of the brain - Subacute brain changes after prophylactic WBRT.

\section{Second clinical case}

We present a 57-year-old woman with solitary intracranial plasmacytoma (SICP). Intensively modulated prophylactic wholebrain radiotherapy (WBRT) with DD 3 Gy up to TD 30 Gy /
Biologically equivalent dose (BED) 38 Gy / 5 times per week was performed. The first local recurrence occured 1.5 years after the WBRT, and the second local recurrence occured 5 months after its surgical extirpation (Figure 5 \& 7/A).

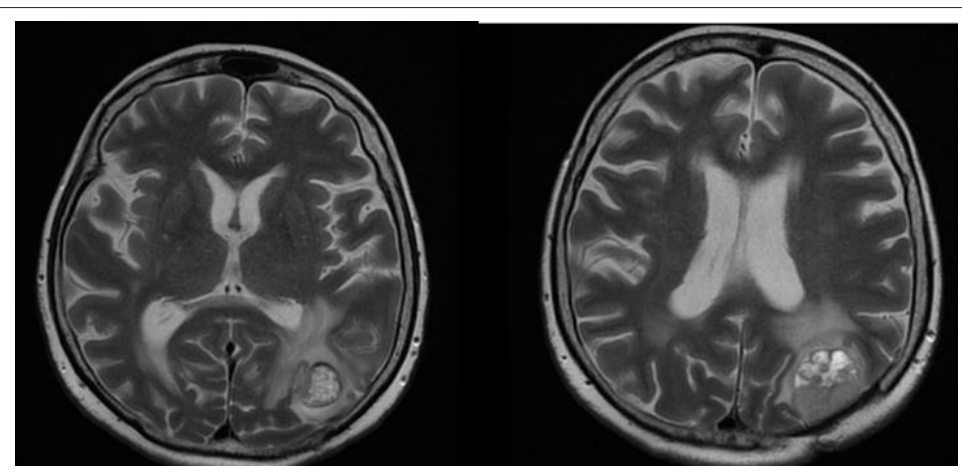

Figure 5: MRI - Second local recurrence of solitary intracranial plasmacytoma after prophylactic whole-brain radiotherapy.

From the studies: Bone scintigraphy, bone marrow biopsy, serum protein immunoelectrophoresis, serum levels of immunoglobulins, serum lactate dehydrogenase, calcium, albumin, renal function, beta-2 microglobulin levels - all without abnormalities. We performed local intensity-modulated radiotherapy (IMRT) by the VMAT method in the area of recurrence up to TD 45 Gy with DD 1.8 Gy / 25 fractions (Figure 6). 

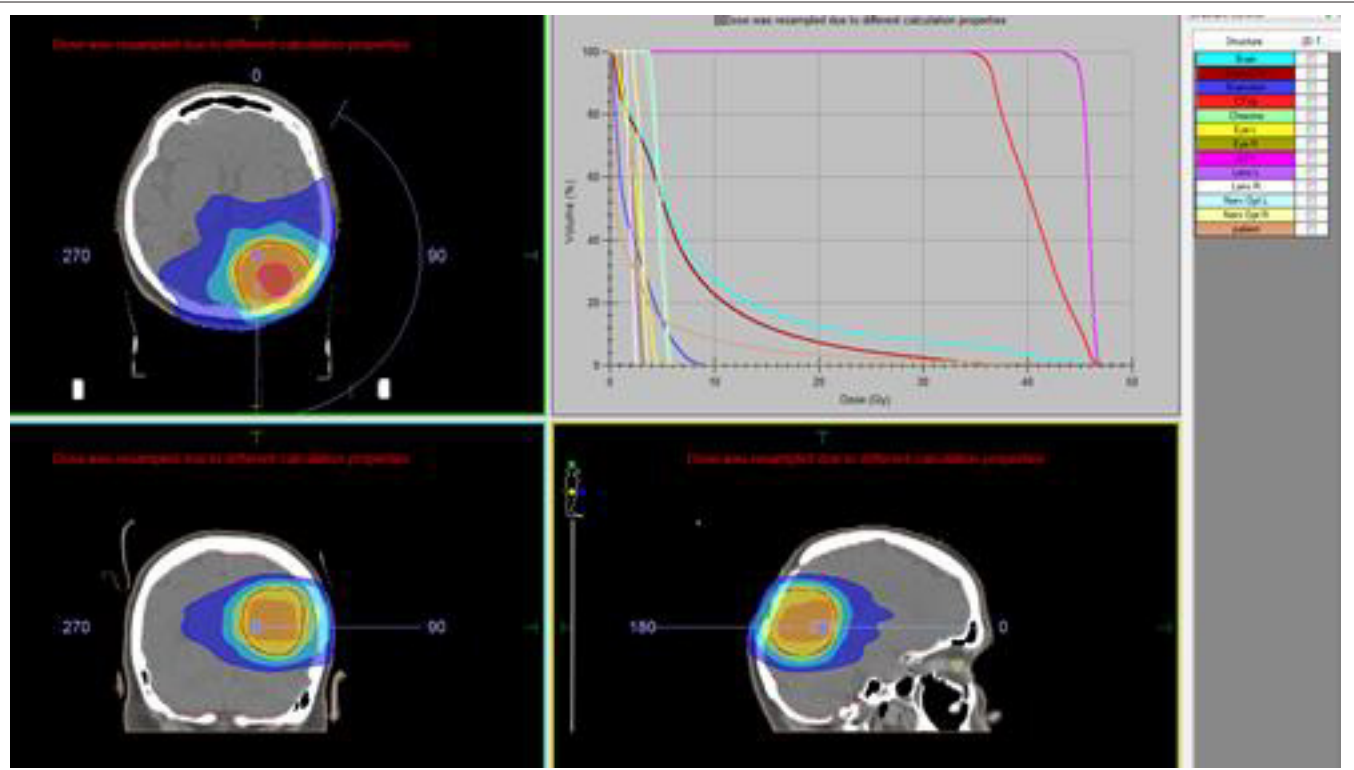

Figure 6: Local IMRT by the VMAT method in the area of second local recurrence of solitary intracranial plasmacytoma up to TD 45 Gy with DD $1.8 \mathrm{~Gy} / 25$ fractions.

Due to seizure symptoms 2 weeks after RT, the irradiated relapse (Figure 7/B) was operated and histologically confirmed as necrotic brain tissue.

\section{Third clinical case}

A 57-year-old man with non-small cell lung cancer NSCLC/ adenocarcinoma is presented. Due to complaints of headache, nausea and vomiting after CT, two brain metastases were proven in the right brain hemisphere with frontal and parietal parasagital localization. The right frontal metastasis with dimensions $32 \mathrm{~mm} /$ $30 \mathrm{~mm}$ was surgically removed. Postoperatively, intensity- modulated WBRT with DD 2.5 Gy up to TD 27.5 Gy with boost in the right parietal parasagital metastasis up to OOD 33 Gy with DOD 3 Gy / total radiobiologically equivalent dose (BED) $60 \mathrm{~Gy}$ was carried out (Figure 8). After 4 months, in another medical institution, despite the lack of cerebral symptoms, local RT by the VMAT method in the area of same metastasis up to TD 20 Gy with DD 4 Gy was performed. After 7 months of the second RT, of CT with venous contrast, a parasagittal cystic lesion up to $14 \mathrm{~mm}$ in size in the right parietal supratentorial area was visualized, most likely a necrotic brain tissue with pronounced frontoparietal edema (Figure 9).

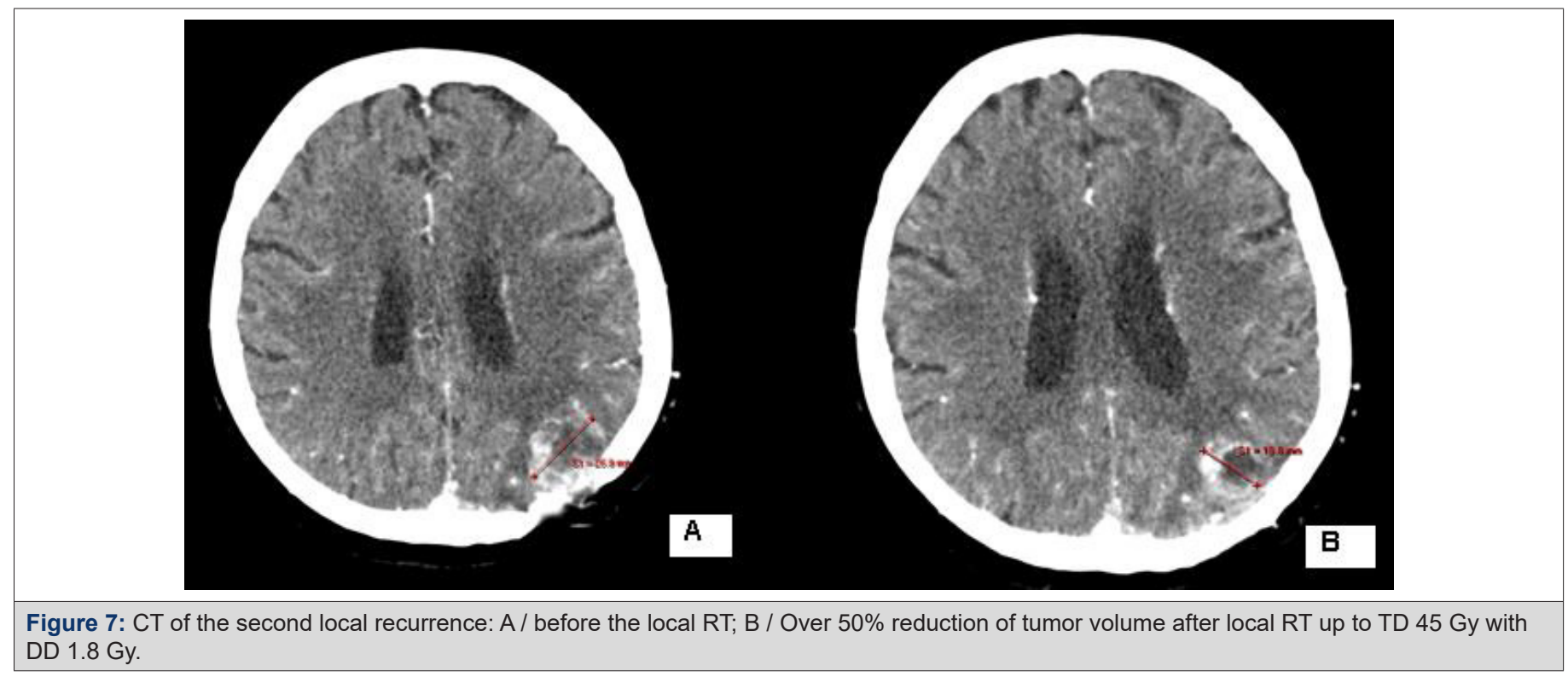



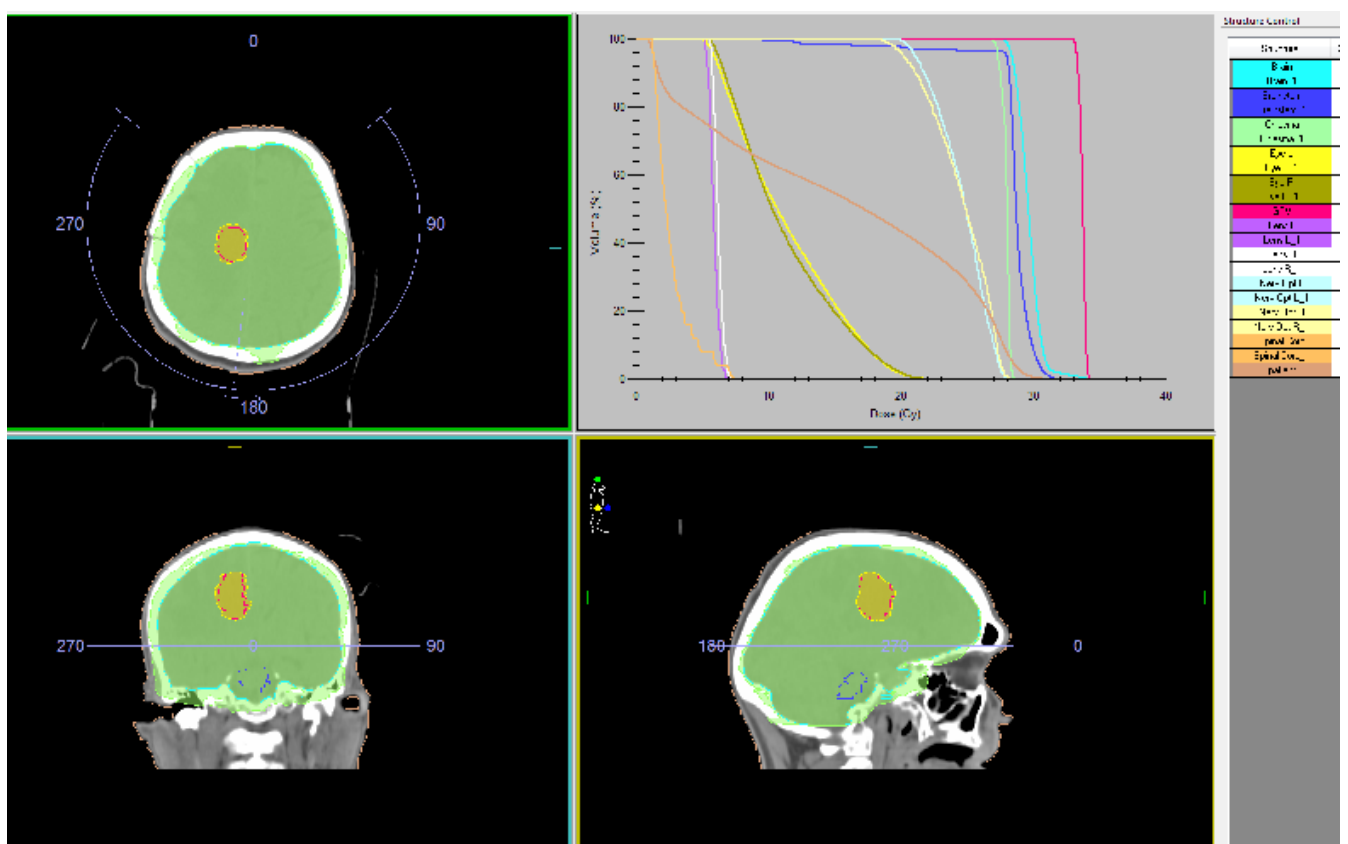

Figure 8: The intensity modulated WBRT with DD 2.5 Gy up to TD 27.5 Gy with boost in the postoperative metastatic bed up to OOD 33 Gy with DOD 3 Gy.
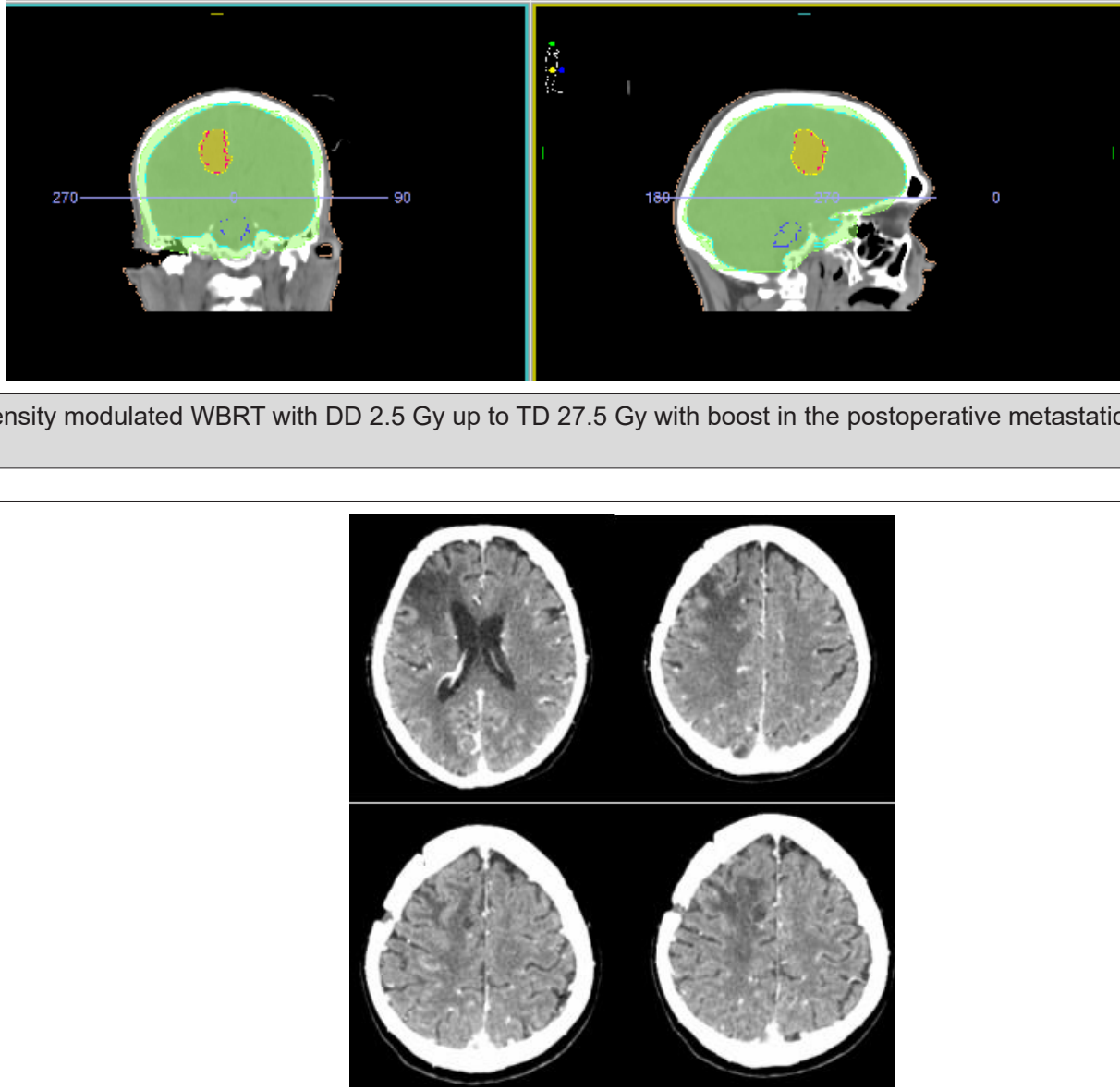

Figure 9: CT of the brain - A parasagittal cystic lesion up to $14 \mathrm{~mm}$ in size in the right parietal supratentorial area with frontoparietal edema, most likely a necrotic brain tissue.

\section{Fourth clinical case}

A 17-year-old boy with extremely rare primary brain neuroblastoma/supratentorial primitive neuroectodermal tumor (PNET) in the right temporo-parietal region is presented. Complex treatment, including subtotal surgery, conventional fractionated craniospinal radiotherapy (CSRT) with DD 1.8 Gy up to TD $30 \mathrm{~Gy}$ with boost RT in the tumor bed up to TD 56 Gy with DD 1.8 Gy and 6 courses of adjuvant Ch (Etoposide and Carboplatin) was conducted (Figure 10). After 2 years of control MRI, a local recurrence was established (Figure 11), in which an additional local RT with DD 2Gy to TD 34Gy was performed. After 7 months of complementary local RT, MRI demonstrated local tumor control (Figure 12).
After three months of MRI, a second local recurrence was diagnosed, which was operated on (Figure 13/A). Postoperative bone marrow transplantation of stem cells was performed, but 1 year later a third local recurrence was diagnosed (Figure 13/B).

The third recurrence was operated. Histological result: Brain tissue with infiltration from nests and derived from small atypical cells with hyperchromic nuclei and visible nucleoli. Tumor cells form pseudosockets. Focal hemorrhages and necrosis are seenHistological data for neuroblastoma. Given the previous peripheral stem cell transplantation and the high risk of hematological toxicity, 6 courses of Ch with Vincristine and Temodal in a reduced dose were administrated. MRI 2 months after the completion of $\mathrm{Ch}$ 
visualized a fourth local recurrence and the patient was referred to radiosurgery with a gamma knife in Turkey where a single TD 14 Gy has been performed. Paresis of the left limbs suddenly occurred 2 months after the procedure. On contrast-enhanced MRI with evidence of subacute hematoma in the postoperative porencephalic cyst in the right temporoparietal brain area (Figure 14/A). CT in 20 days reported a persistent subacute hematoma in the right temporoparietal postoperative porencephalic cyst (Figure 14/ B).

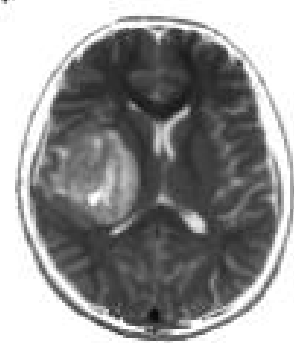

A

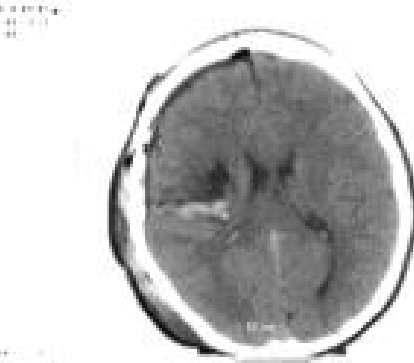

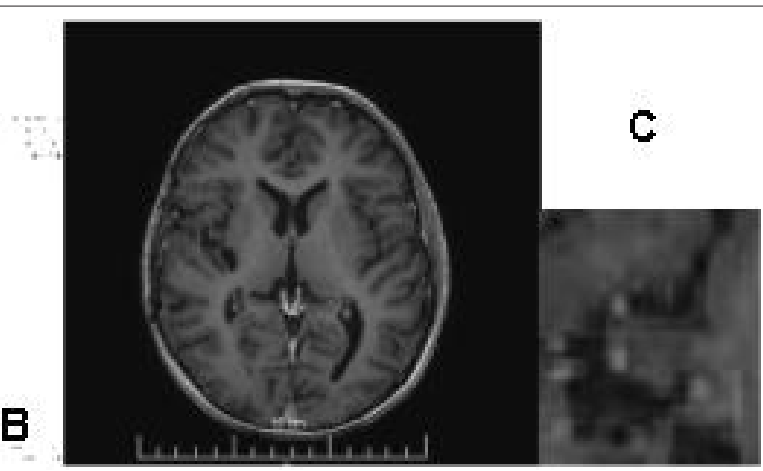

Figure 10: MRI of primary brain neuroblastoma: A / Preoperative; C / Postoperative; C / Local tumor control after complex treatment / subtotal surgery, CSRT with boost RT in the tumor bed up to $56 \mathrm{~Gy}$ and 6 cycles of chemotherapy according to the BEP protocol.

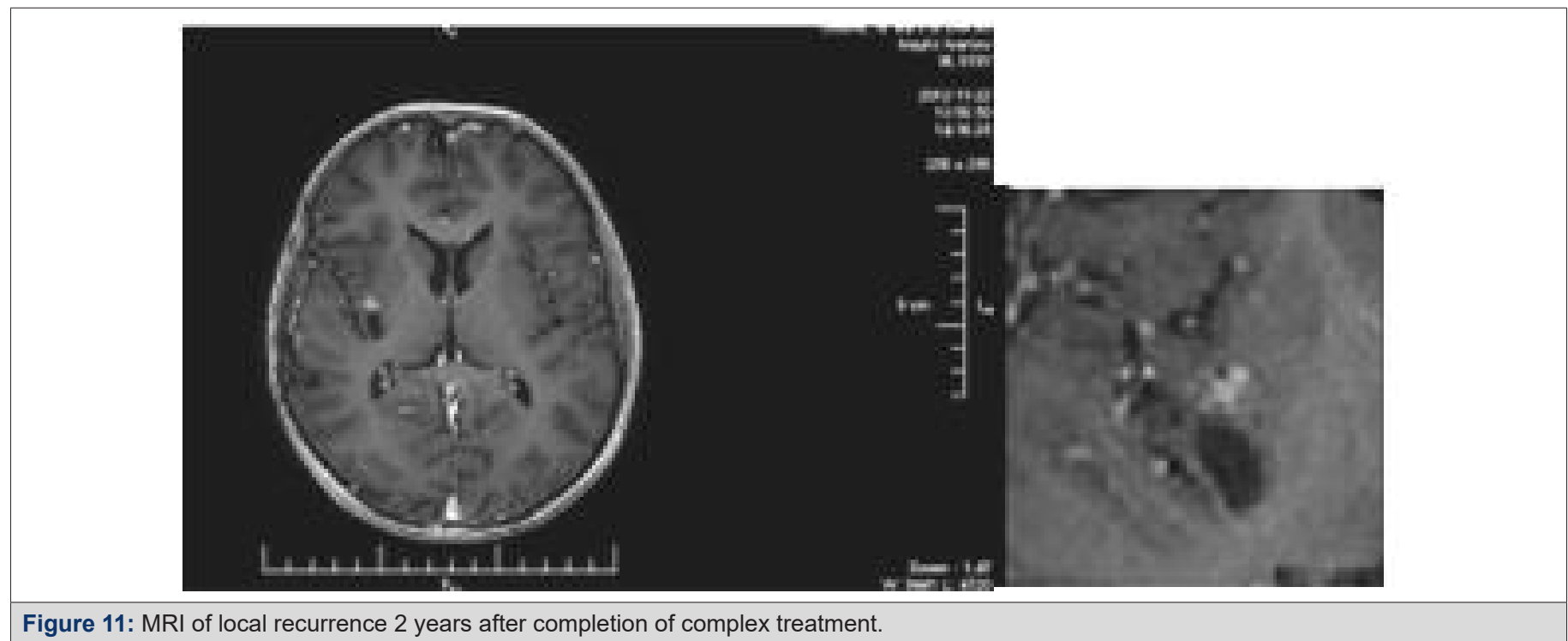

Figure 11: MRI of local recurrence 2 years after completion of complex treatment.

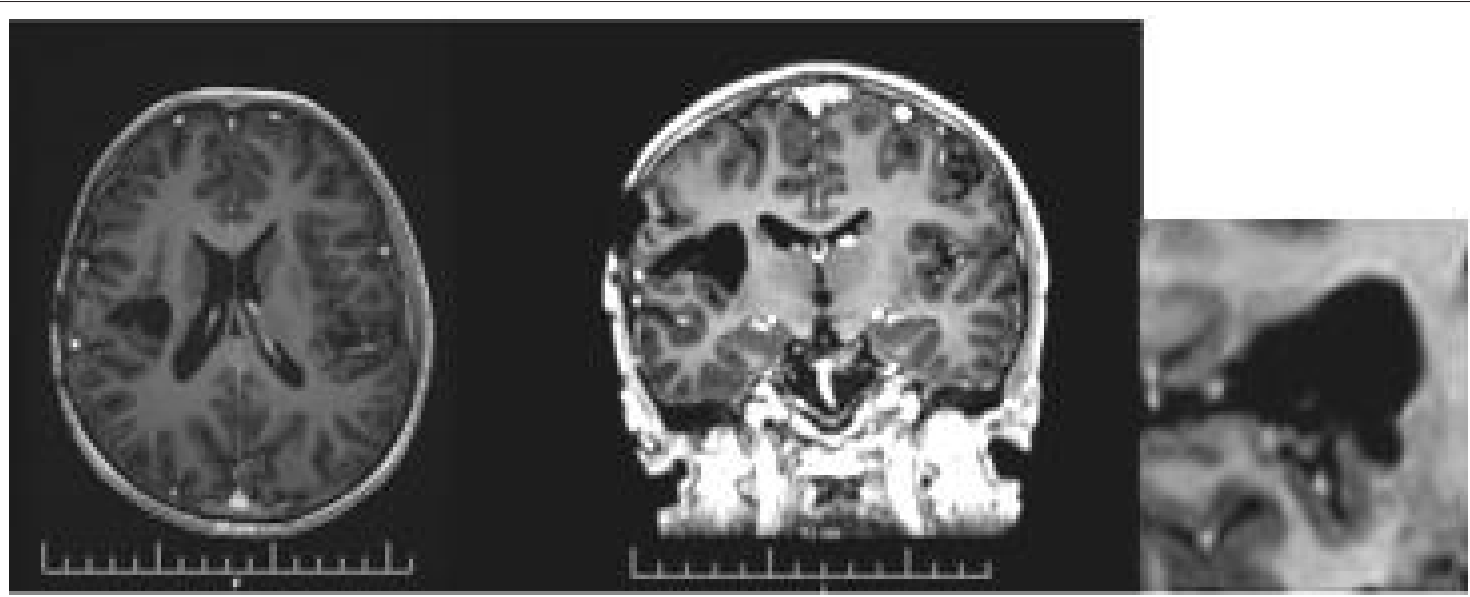

Figure 12: MRI after 7 months of complementary local RT with achieved local tumor control. 


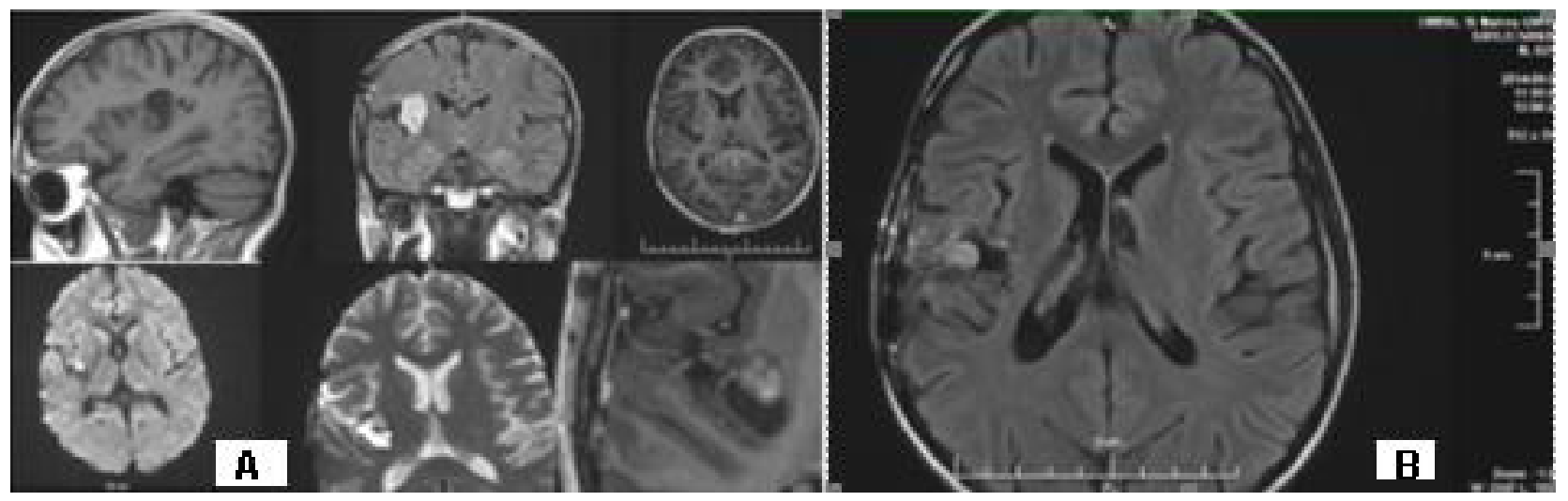

Figure 13: $\mathrm{A} / \mathrm{MRI}$ of the second local recurrence; $\mathrm{B} / \mathrm{MRI}$ of the third local recurrence after 1 year of bone marrow transplantation

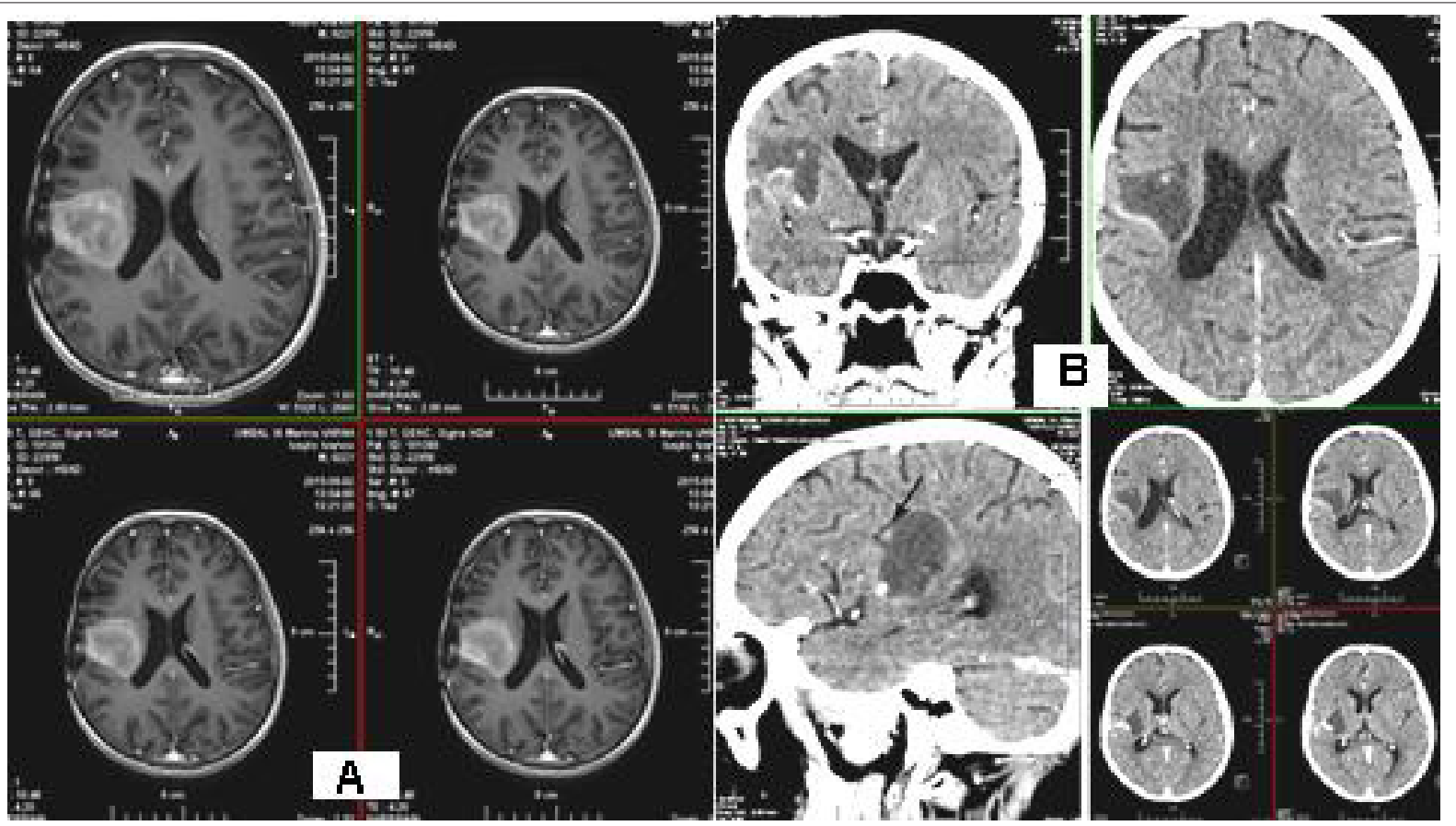

Figure 14: $\mathrm{A} / \mathrm{MRI}$ - Subacute hematoma in the postoperative right temporoparietal porencephalic cyst after radiosurgery with a gamma knife with a single TD $14 \mathrm{~Gy}$; B/ CT after 20 days- subacute hematoma in the postoperative right temporoparietal porencephalic cyst.

\section{Discussion}

Due to the development of the imaging diagnosis and the efficacy of complex oncology treatment, there is a significantly increased overall survival of patients with malignancies. On this background, clinical cases with brain metastases are also increasing. In addition to surgery, their treatment involves the application of various radiotherapeutic techniques with different radiation volumes and fractionation of the radiation dose.

\section{Prophylactic whole-brain radiotherapy (PWBRT)}

The whole-brain radiotherapy (WBRT) is conducted for two therapeutic purposes - preventive or prophylactic and curative. PWBRT is a standard approach in the limited or advanced stage of small cell lung cancer (SCLC) in clinical remission after systemic chemotherapy (Ch) and local pulmonary radiotherapy (RT).
Without PWBRT, $60 \%$ of SCLCs develop brain metastases (BM), and they are reduced to $20 \%$ after it was performed [10]. PWBRT is also recommended for non- small cell lung cancer (NSCLC) [11-15], in which a significant reduction in BM of $18 \%$ to $8 \%$ without improved overall survival (OS) has been achieved [16] in contrast to SCLC, where OS is significantly increased $[17,18]$. The purpose of PWBRT is to destroy microscopic metastatic tumor cells in the brain before their clinical manifestation. Radiation brain effects after PWBRT are divided into acute, subacute and chronic [19]. Acute side effects occur during or one to two weeks after completion of PWBRT. They are expressed by general fatigue, alopecia and symptoms associated with increased cerebral edema - headache, nausea, focal brain deficits, a pronounced mental change [20]. These acute symptoms gradually subside in a large proportion of patients. On MRI, diffuse cerebral edema is visualized [21]. Subacute symptoms 
develop immediately after the completion of RT or three months after its completion. They are relatively rare and limited, mainly to drowsiness syndrome and less commonly as leukoencephalopathy [20]. 3 months after 10x3Gy PWBRT, the condition of a 73-yearold SCLC patient, who underwent 6 courses of Ch (Cisplatin and Etoposide) deteriorated. CT and MRI visualize extensive cerebral edema in the left hemisphere, without brain metastases (Figure 3 \& 4). In children with leukemia after PWBRT, there is a "radiation somnolence syndrome" characterized by somnolence often associated with headache, nausea, vomiting and sometimes fever. The necessary treatment is the administration of corticosteroids, but it should be noted that these complaints may resolve spontaneously [22]. Somnolence is more common in children with PWBRT with concomitant chemotherapy (methotrexate/ intrathecal) [23]. Pathophysiologically, this somnolent syndrome is associated with transient demyelination of the white matter. On the other hand, it should be noted that leukoencephalopathy is considered a more severe manifestation of demyelination and may be fatal. These changes in white matter are much more common in adult patients with concomitant chronic cerebrovascular ischemia [20]. Symptoms are usually mild and stabilize or resolve. Imaging CT and MRI with intravenous contrast varies from diffuse cerebral edema to increased accumulation of contrast [21]. In the presented adult patient it can be seen that against the background of antiedema medication treatment (Dexamethasone and Mannitol), the symptoms was not transient, on the contrary, they worsen (Figure 3 \& 4). Subacute encephalopathy usually begins two or three months after cerebral RT but may occur 2 weeks to 4 months after completion of PWBRT. It is usually seen in patients with SCLC after chemotherapy of the primary tumor. The pathogenesis of subacute encephalopathy is due to demyelination due to damage to the oligodendroglia with subsequent involvement of the myelin sheaths [22]. The progression of these changes leads to late effects manifested by radionecrosis [23-25]. Tissue necrosis is a distinct syndrome of radiation toxicity, thought to be the consequence of vascular endothelial cell damage, resulting in fibrinoid necrosis of small vessels and direct brain parenchymal necrosis. Occlusion of small blood vessels results in focal coagulative necrosis, capillary leakage, and demyelination of the surrounding brain parenchyma $[26,27]$. The relationship between PWBRT and late brain toxicity was analyzed in 264 patients with limited stage SCLC [28]. Patients are divided into 3 arms depending on the DD and the TD: 10 fractions up to TD 25 Gy; 18 fractions up to TD 36 Gy and hyperfractionated RT ( two daily fractions) with 24 fractions up to TD 36 Gy. Neurological changes are reported after 6 months and 12 months of PWBRT. After 1 year, neurotoxicity was established in $60 \%$ of patients after TD 25 Gy and in $80-90 \%$ after TDs 36 Gy.

\section{Curative whole-brain radiotherapy (WBRT)}

Brain metastases represent a significant cause of cancer morbidity, occurring in around $30 \%$ of patients with a malignancy originating outside the central nervous system [29]. The management of intracranial metastatic disease is made complicated by the impermeability of the blood-brain barrier to many chemotherapeutic agents, rendering this region a 'sanctuary site' for malignancies, most commonly breast, lung, melanoma, and renal cell carcinoma [30]. WBRT was the historic standard of care prior to the widespread use of radiosurgery (RS) [31]. For patients with multiple brain metastases or presenting with uncontrolled primary tumor or multiple extracerebral metastases, WBRT is the treatment of choice, associated with corticosteroids as symptomatic treatment. Fractionation schedules are varied (30 Gy in 10 fractions, 20 Gy in 4 or 5 fractions), but none has proven superiority in terms of prolonging OS [32]. Still, it has been postulated that patients with a more favorable survival prognosis could benefit from a protracted radiotherapy (RT) regimen, whereas patients with a poorer prognosis should receive shorter course RT [33]. For the statistical analysis of these heterogeneous regimens, total doses were normalized to 2 Gy and the biologically equivalent dose (BED) was calculated, with a $\alpha / \beta$ ratio of 3 , for long term toxicities in brain tumors [34]. There are different opinions about the radiation toxicity on the cognitive brain function after WBRT - no changes, reported adverse effects and even initial improvement [35-40]. However, the principle concern with WBRT, particularly in patients with a more favourable prognosis, is the negative impact on neurocognitive function and quality of life [41]. WBRT in brain metastases has been associated with subacute and late neurotoxicity, causing reduced cognitive function, including reduced memory [20]. The second clinical case is an extremely rare extramedullary brain plasmocytoma (EMBP) with intracranial localization [42]. Craniocerebral solitary plasmocytom may occur from the skull (the grain or cranial base), the solid brain sheath and less frequently in the brain parenchyma [43].

There are two forms of the solid craniocerebral plasmocytoma:

1. Primary plasmocytom expanding from the cranial bones and

2. Intracranial extramedullary pasmocytom of the solid brain shell or less than the brain parenchyma [44-48].

There are publications for full cure after biopsy and local RT, as solitary plasmocellular neoplasms are extremely radiosensitive [49]. In EMBP after self-RT without surgery, increased OS has been reported [50]. RT up to TD 50 Gy for 5 weeks on the cranial base EMP achieves excellent healing output and local tumor control (LTC) over 85\% [51]. Optimal treatment in most patients with EMBP is local RT up to TD 40-50 Gy with DD 1.8-2 Gy [52]. After operating in the clinical case with EMBP, the WBRT (10 fractions with DD 3Gy up to TD 30 - BED 38 Gy) was conducted, instead of local radiation in the tumor bed up to TD 50Gy. This is the reason 
for the first recurrence, that was operated. Subsequently, after one year, a second recurrence appears, which we irradiated locally up to TD 45Gy (Figure 6). Although the total BED does not exceed 100Gy, due to the extremely radiosensitiv plasmocytoma, brain tissue necrosis develops (Figure 7/B).

\section{Whole-brain radiotherapy with boost $\mathrm{RT}$}

Although different fractionation schedules of WBRT do not influence survival [32], it appears that escalating the dose to the metastatic lesions increases intracerebral control as well as OS, compared to WBRT alone [53,54]. WBRT with 3D conformal boost is a feasible technique which improves the quality of life (QOL) of patients with a reduced number of brain metastases, regardless of the fractionation regimen or the total dose administered to the metastatic lesions [34]. In the third clinical case, with NSCLC after WBRT with VMAT boost in the brain metastasis to cumulative biological equivalent dose (BED) 60 Gy (Figure 8), a second hypofractionated Intensity modulated Re-irradiation with DD 4 Gy up to TD 20 Gy was conducted. Late side effects appear after 6 months of RT or later include visible radionecrosis of the brain with fields of focal coagulation necrosis and progressive microvascular occlusion with increased risk of stroke [55-58]. Data exist concerning the re-irradiation of brain tumors to a median cumulative BED (biological equivalent dose in 2Gy fractions) of 200Gy, with at least one year between the two treatments. Longterm complications related to the retreatment were seen in patients with a BED2>204Gy ( $\alpha$ : $\beta=2$ Gy) [59]. Although the BED does not exceed $200 \mathrm{~Gy}$, the radionecrosis of the clinical case is due to the short time (less than 6 months) between the retreatment as well as the high daily dose of 4 Gy (Figure 9).

\section{Stereotactic radiosurgery (SRS)}

Improvements in systemic disease control combined with recognition of WBRT toxicity have led to stereotactic radiosurgery (SRS) becoming considered a standard of care in patients with 1-3 metastases. After 6 months of SRS in the area of apparently removed metastasis, lower levels of neurocognitive deterioration are reported compared to post-operative WBRT and despite lower local control, survival rates are equivalent [60]. Using a mini mental state examination (MMSE), Aoyama et al. assessed 132 patients randomised to SRS alone versus SRS with WBRT and they reported no differences in overall survival [61]. A multi-centre European study randomised 359 patients with 1-3 metastases undergoing SRS or surgery between observation and adjuvant WBRT. There was no difference in the primary endpoint of duration of patients' functional independence ( $p=0.89$ ) [62]. A secondary endpoint was quality of life and patients had significantly higher global health related quality of life mean scores at 9 months with observation alone [63]. Aoyama et al. [64] published in 2015 the results of a secondary analysis of the Japanese Radiation Oncology Study Group trial comparing RSR+WBRT versus SRS alone in oligometastatic patients and concluded that the addition of WBRT significantly improved OS in patients with good prognosis, highlighting its role in this patient subset. Following the earlier pilot study, a randomized trial to evaluate the effect of adding WBRT (30 Gy) to SRS (18-24 Gy) on cognitive function in patients with 1 to 3 BM was conducted [65]. The results showed significant Bayesian probability (with $96 \%$ confidence) of deterioration on the verbal learning and memory test at 4 months in patients treated with both modalities compared with patients treated with SRS only. Radiation can result in a chronic inflammatory response that influences hippocampal cell proliferation, which has stimulated interest in trials using anti-inflammatory agents to prevent radiation injury. In addition, research has shown that damage to the hippocampus that is caused by radiation can lead to impairments in learning, (short-term) memory, and spatial processing [66,67]. By avoiding the hippocampal neural stem cells during WBRT, cognitive decline might be prevented or minimized [68].

In the fourth clinical case, the young boy with the rare diagnosis of brain neuroblastoma (PNET) concerns extremely malignant neoplasm. Complex treatment, including subtotal surgery, conventional fractionated craniospinal radiotherapy (CSRT) with DD 1.8 Gy up to TD 30 Gy with boost RT in the tumor bed up to TD 56 Gy with DD 1.8 Gy and 6 courses of adjuvant Ch (Etoposide and Carboplatin) was applied (Figure 10). After 2 years of control MRI, a local recurrence was established (Figure 11), in which an additional local RT with DD 2Gy to TD 34Gy was performed. The prognosis and survival directly depend on the volume of the surgery, the magnitude of the postoperative brain residue $(>1.5$ $\mathrm{cm} 2$ ), the infiltration of the IV ventricle and the pathohistological cell variant $[69,70]$. Subtotal surgical resection and evidence of disease dissemination are considered poor prognostic factors [71]. In adult patients, the five-year progression-free survival rate ranges from $45 \%$ to $78 \%$ depending on the risk class [72-74]. In the young patient with a primary brain PNET, the bone marrow transplantation with stem cells was conducted, 1 year after which we diagnosed third local recurrence (Figure 13). For a period of 5 years, despite complex treatment, including subtotal surgery, conventional fractionated CSRT with boost, $\mathrm{Ch}$, local RT and bone marrow transplantation, 2 months after the completion of $\mathrm{Ch}$ on MRI, a fourth local recurrence occurred, subjected to radiosurgery with a gamma knife in Turkey with a single fraction 14 Gy. After 2 months from SRS, contrast-enhanced MRT reported evidence of late subacute hematoma in the postoperative porencephalic cyst in the right temporoparietal brain area (Figure 14/A). CT in 20 days reported a persistent subacute hematoma in the right temporoparietal postoperative porencephalic cyst (Figure 14/B). 


\section{Possible preventive measures to minimize early and late brain toxicity}

i. The standard recommended prophylactic dose is 25 Gy in 10 fractions [75]. In patients over 60 years of age with vascular changes, the daily doses of PWBRT should be lower - 15 fractions with DD 2 Gy up to TD 30 Gy. Patients with SCLC are risky with regard to cognitive deficiency in age-related brain atrophy, existing cerebrovascular diseases, anxiety, depression and $\mathrm{Ch}$ effects. In the absence of these risk factors there are disputes concerning the contribution of PWBRT to observed neurological deficits [76].

ii. In the RT planning of PWBRT or of culture WBRT, maximum preserving the hippocampus was recommended [77-79]. This is a radiosensitive brain area, localized ventricular from the temporal brain, lie back from the amygaloid complex and laterally from the temporal ventricular horn [80]. Its preservation should lead to a lower level of reduced memory $[35,77,79,81-89]$. This is possible with spiral tomotherapy PWBRT (15 fractions with DD 2 Gy up to TD 30 Gy), wherein the minimization of the middle dose in the hippocampus is up to 11.7 Gy [90].

iii. The human brain contains areas with mitotically active cells that retain their ability to divide and differentiation in neural or glial brain cells throughout life [91]. They are known as neural stem cells, which are located in two specific brain areas in the subgranular zone in the dentate girus (part of the hippocampus) and the subventricular zone adjacent to the lateral part of the temporal horn and the occipital part of lateral ventricles $[92,93]$. These cells can migrate into the brain to the affected areas to settle in the neural cortical or white brain damage $[94,95]$. The preservation of neural stem cells during PWBRT and culture WBRT should affect the possibility of restoring induced brain damage from cranial RT and help keep the neurological function. A dosimetric reduction in these zones with intensive modulated WBRT is possible [96].

iv. Re-irradiation is frequently undertaken for isolated brain relapses. A meta-analysis of brain re-irradiation found no cases of necrosis if the TD lower than 100Gy (2 Gy daily fraction dose; $\alpha: \beta=2$ Gy) was [97]. In humans, there is evidence that the risk of myelopathy is low at radiation doses up to a median cumulative BED 135Gy, when the time interval between reirradiation is not shorter than six months and the dose for each course is <98Gy BED [98].

v. Large BM can be defined according to their diameter or volume, with lesions measuring either $\geq 2$ or $\geq 3 \mathrm{~cm}$ in diameter or $\geq 4 \mathrm{~cm} 3$ [99-105] being considered in this category. The combination of surgery with post operative radiation either to the cavity or to the whole brain (WBRT), SRS alone or hypofractionated RT have been proposed to address these tumors [100-106]. Treatment can be administered using different delivery systems and is usually linear-accelerator based to avoid head frame fixation as patients are usually treated with multiple fractions. Hypofractionated RT is a viable alternative to WBRT for the upfront treatment of brain metastasis that are not amenable to radiosurgery or surgery, or in the postoperative setting [107]

\section{Conclusion}

Due to the development of the imaging diagnosis and the efficacy of complex oncology treatment, there is a significantly increased overall survival of patients with malignancies. On this background, clinical cases with brain metastases are also increasing. In patients over 60 years of age with vascular changes, the daily doses of PWBRT should be lower - 15 fractions with DD 2 Gy up to TD 30 Gy. In the RT planning of PWBRT or culture WBRT, maximum preserving the hippocampus was recommended. This is possible with spiral tomotherapy PWBRT (15 fractions with DD 2 Gy up to TD $30 \mathrm{~Gy}$ ), wherein the minimization of the middle dose in the hippocampus is up to $11.7 \mathrm{~Gy}$. The preservation of neural stem cells during intensive modulated WBRT should affect the possibility of restoring induced brain damage from cranial RT and help keep the neurological function. There is evidence that the risk of myelopathy is low at radiation doses up to a median cumulative BED 135Gy, when the time interval between re-irradiation is not shorter than six months and the dose for each course is <98Gy BED.

\section{References}

1. Nichols EM, Patchell RA, Regine WF, Kwok Y (2013) Palliation of brain and spinal cord metastases. In: Halperin EC, Wazer DE, et al. (Eds.), Principles and practice of radiation oncology. $6^{\text {th }}$ edn, Lippincott Williams \& Wilkins, Philadelphia, USA, pp. 1766-1778.

2. Walker AE, Robins M, Weinfield FD (1985) Epidemiology of brain tumors: the national survey of intracranial neoplasms. Neurology 35(2): 219-226.

3. Loeffler JS, Patchell RA, Sawaya R (1997) Treatment of metastatic cancer. In: Devita VT, Hellman S, (Eds.), Cancer: Principles and Practice of Oncology. Lippincott-Raven, Philadelphia, USA, pp. 2523.

4. Arvold ND, Lee EQ, Mehta MP, Margolin K, Alexander BM, et al. (2016) Updates in the management of brain metastases. Neuro Oncol 18(8): 1043-1065.

5. Lippitz B, Lindquist C, Paddick I, Peterson D, O’Neill K, et al. (2014) Stereotactic radiosurgery in the treatment of brain metastases: The current evidence. Cancer Treat Rev 40(1): 48-59.

6. Tabouret E, Chinot $\mathrm{O}$, Metellus $\mathrm{P}$, Agnès Tallet, Patrice Viens, et al. (2012) Recent trends in epidemiology of brain metastases: An overview. Anticancer Res 32: 4655-4662.

7. Rades D, Pluemer A, Veninga T, Juergen Dunst, Steven E Schild (2007) A boost in addition to whole-brain radiotherapy improves patient outcome after resection of 1 or 2 brain metastases in recursive partitioning analysis class 1 and 2 patients. Cancer 110(7): 1551-1559. 
8. De Potter B, De Meerleer G, De Neve W, Boterberg T, Speleers B, et al (2013) Hypofractionated frameless stereotactic intensity-modulated radiotherapy with whole brain radiotherapy for the treatment of 1-3 brain metastases. Neurol Sci 34: 647-653.

9. Andrews DW, Scott CB, Sperduto PW, Flanders AE, Gaspar LE, et al. (2004) Whole brain radiation therapy with or without stereotactic radiosurgery boost for patients with one to three brain metastases: phase III results of the RTOG 9508 randomised trial. Lancet 363: 1665-1672.

10. Samson DJ, Seidenfeld J, Simon GR, Turrisi AT, Bonnell C, et al. (2007) Evidence for management of small cell lung cancer: ACCP evidence-based clinical practice guidelines (2nd edition) Chest 132(3): 324S-339S.

11. Lester JF, MacBeth FR, Coles B (2005) Prophylactic cranial irradiation for preventing brain metastases in patients undergoing radical treatment for non-small-cell lung cancer: a cochrane review. Int J Radiat Oncol Biol Phys 63(3): 690-694.

12. Stuschke M, Eberhardt W, Pöttgen C, Stamatis G, Wilke H, et al. (1999) Prophylactic cranial irradiation in locally advanced non-small-cell lung cancer after multimodality treatment: long-term follow-up and investigations of late neuropsychologic effects. Journal of Clinical Oncology 17(9): 2700-2709.

13. Stuschke M, Pöttgen C (2003) Prophylactic cranial irradiation as a component of intensified initial treatment of locally advanced non-small cell lung cancer. Lung Cancer 42(2): S53-S56.

14. Pöttgen C, Eberhardt W, Grannass A, Korfee S, Stüben G, et al. (2007) Prophylactic cranial irradiation in operable stage IIIA non-small-cell lung cancer treated with neoadjuvant chemoradiotherapy: results from a German multicenter randomized trial. Journal of Clinical Oncology 25(31): 4987-4992.

15. Topkan E, Yildirim BA, Selek U, Yavuz MN (2009) Cranial prophylactic irradiation in locally advanced non-small cell lung carcinoma: current status and future perspectives. Oncology 76(3): 220-228.

16. Movsas B (2009) Phase III study of prophylactic cranial irradeiation (PCI) vs. observation in patients with stage III nonsmall-cell lung cancer (NSCLC): neurocognitive and quality of life (QOL): analysis of RTOG 0214 .

17. Aupérin A, Arriagada R, Pignon JP (1999) Prophylactic cranial irradiation for patients with small-cell lung cancer in complete remission. New England Journal of Medicine 341(7): 476-484.

18. Slotman B, Faivre-Finn C, Kramer G (2007) Prophylactic cranial irradiation in extensive small-cell lung cancer. New England Journal of Medicine 357(7): 664-672

19. Cross NE, Glantz MJ (2003) Neurologic complications of radiation therapy. Neurologic Clinics 21(1): 249-277.

20. James CM, Gielda BT, Herskovic AM, Abrams RA (2010) Cognitive Sparing during the Administration of Whole Brain Radiotherapy and Prophylactic Cranial Irradiation: Current Concepts and Approaches. J Oncol 2010: 198208

21. Walker AJ, Ruzevick J, Malayeri AA, Rigamonti D, Lim M, et al. (2014) Postradiation imaging changes in the CNS: how can we differentiate between treatment effect and disease progression? Future Oncol 10(7): 1277-1297.

22. Moraes FY, Shultz DB, Murphy ES (2017) Strategies to mitigate the effects of whole-brain radiation therapy on neurocognitive function in patients with brain metastases. Appl Rad Oncol 6(1): 6-10.

23. Freeman JE, Johnston PG, Voke JM (1973) Somnolence after prophylactic cranial irradiation in children with acute lymphoblastic leukaemia. $\mathrm{Br}$ Med J 4(5891):523-525.

24. Leibel SA, Sheline GE (1987) Radiation therapy for neoplasms of the brain. J Neurosurg 66(1): 1-22.
25. Rane N, Quaghebeur G (2012) CNS effects following the treatment of malignancy. Clin Radiol 67(1): 61-68.

26. Burger P, Boyko OB (1991) The pathology of central nervous system radiation injury. In: Radiation injury to the nervous system, Raven Press, New York, USA, p. 191.

27. Burger PC, Mahley MS Jr, Dudka L, Vogel FS (1979) The morphologic effects of radiation administered therapeutically for intracranial gliomas: a postmortem study of 25 cases. Cancer 44(4): 1256.

28. Wolfson AH, Bae K, Komaki R, Meyers C, Movsas B, et al. (2011) Primary Analysis of a Phase II Randomized Trial Radiation Therapy Oncology Group (RTOG) 0212: Impact of Different Total Doses and Schedules of Prophylactic Cranial Irradiation on Chronic Neurotoxicity and Quality of Life for Patients with Limited-Disease Small-Cell Lung Cancer. Int J Radiat Oncol Biol Phys 81(1): 77-84.

29. Frisk G, Svensson T, Bäcklund LM, Lidbrink E, Blomqvist P, et al. (2012) Incidence and time trends of brain metastases admissions among breast cancer patients in Sweden. Br J Cancer 106: 1850-1853.

30. Schouten LJ, Rutten J, Huveneers HA, Twijnstra A (2002) Incidence of brain metastases in a cohort of patients with carcinoma of the breast, colon, kidney, and lung and melanoma. Cancer 94(10): 2698-2705.

31. Borgelt B, Gelber R, Kramer S, Brady LW, Chang CH, et al. (1980) The palliation of brain metastases: Final results of the first two studies by the radiation therapy oncology group. Int J Radiat Oncol Biol Phys 6(1): 1-9.

32. Tsao MN, Xu W, Wong RK, Lloyd N, Laperriere N, et al. (2018) Whole brain radiotherapy for the treatment of newly diagnosed multiple brain metastases. Cochrane Database Syst Rev 1(1): CD003869.

33. Rades D, Dziggel L, Nagy V, Segedin B, Lohynska R, et al (2013) A new survival score for patients with brain metastases who received wholebrain radiotherapy (WBRT) alone. Radiother Oncol 108: 123-127.

34. Suteu P, Fekete Z, Todor N, Nagy V (2019) Survival and quality of life after whole brain radiotherapy with 3D conformal boost in the treatment of brain metastases. Med Pharm Rep 92(1): 43-51.

35. Welzel G, Fleckenstein K, Schaefer J, Hermann B, Kraus-Tiefenbacher U, et al. (2008) Memory function before and after whole brain radiotherapy in patients with and without brain metastases. International Journal of Radiation Oncology Biology Physics 72(5): 1311-1318.

36. Byrne TN (2005) Cognitive sequelae of brain tumor treatment. Current Opinion in Neurology 18(6): 662-666.

37. Gregor A, Cull A, Stephens RJ, Kirkpatrick JA, Yarnold JR, et al. (1997) Prophylactic cranial irradiation is indicated following complete response to induction therapy in small cell cancer: results of a multicentre randomised trial. European Journal of Cancer 33(11): 1752-1758.

38. Ahles TA, Silberfarb PM, Herndon J, Maurer LH, Kornblith AB, et al (2006) Psychologic and neuropsychologic functioning of patients with limited small-cell lung cancer treated with chemotherapy and radiation therapy with and without warfarin: a study by the Cancer and Leukemia Group B. Journal of Clinical Oncology 24: 1295-1304.

39. Regine WF, Scott C, Murray K, Curran W (2001) Neurocognitive outcome in brain metastases patients treated with accelerated-fractionation vs. accelerated-hyperfractionated radiotherapy: an analysis from Radiation Therapy Oncology Group Study 91-04. Int J Radiat Oncol Biol Phys 51(3): 711-717

40. Komaki R, Meyers CA, Shin DM, Garden AS, Byrne K, et al. (1995) Evaluation of cognitive function in patients with limited small cell lung cancer prior to and shortly following prophylactic cranial irradiation. International Journal of Radiation Oncology Biology Physics 33(1): 179182.

41. Pinkham MB, Sanghera P, Wall GK, Dawson BD, Whitfield GA, et al. (2015) Neurocognitive effects following cranial irradiation for brain metastases. Clin Oncol 27(11): 630-639. 
42. Schwartz TH, Rhiew R, Isaacson SR, Orazi A, Bruce JN, et al. (2001) Association between intracranial plasmacytoma and multiple myeloma: clinicopathological outcome study. Neurosurgery 49(5): 1039-1044.

43. Anoop TM, Jain N, Sreejith GN (2014) Intracranial plasmacytoma mimicking meningioma. J Neurosci Rural Practice 5(1): 87.

44. Du Preez JH, Branca EP (1991) Plasmocytoma of the skull: case reports. Neurosurgery 29(6): 902-906.

45. Pritchard PB, Martinez RA, Hungerford GD (1983) Dural plasmocytoma. Neurosurgery 12(5): 576-579.

46. Krumholz A., Weiss HD, Jiji VH, Bakal D, Kirsh MB (1982) Solitary intracranial plasmocytoma: two patients with extended follow up. Ann Neurol 11(5): 529-532.

47. International Myeloma Working Group (2003) Criteria for the classification of monoclonal gammopathies, multiple myeloma and related disorders: a report of the International Myeloma Working Group. Br J Haematol 121(5): 749-757.

48. Bachar G, Goldstein D, Brown D, Tsang R, Lockwood G, et al. (2008) Solitary extramedullary plasmacytoma of the head and neck -- long term outcome analysis of 68 cases. Head Neck 30(8): 1012-1019.

49. Strojan P, Oba E, Lamovec J (2002) Extramedullary plasmacytoma: clinical and histopathological study. Int J Radiat Oncol Biol Phys 53(3): 692-701.

50. Grammatico S, Scalzulli E, Petrucci MT (2017) Solitary Plasmacytoma. Mediterr J Hematol Infect Dism 9(1): e2017052.

51. Gagliardi F, Losa M, Boari N, Spina A, Reni M, et al. (2013) Solitary clival plasmocytomas: misleading clinical and radiological features of a rare pathology with a specific biological behaviour. Acta Neurochirurgica 155: $1849-1856$.

52. Kocak E, Ldllerini G, Zouhair A, Ozsahin M (2010) Radiation therapy for the solitary plasmocytoma. Turk J Hematol 27(2): 57-61.

53. Heisterkamp C, Haatanen T, Schild SE, Rades D (2010) Dose escalation in patients receiving whole-brain radiotherapy for brain metastases from colorectal cancer. Strahlenther Onkol 186(2): 70-75.

54. Sperduto PW, Shanley R, Luo X, Andrews D, Werner-Wasik M, et al. (2014) Secondary analysis of RTOG 9508, a phase 3 randomized trial of wholebrain radiation therapy versus WBRT plus stereotactic radiosurgery in patients with 1-3 brain metastases; poststratified by the graded prognostic assessment (GPA)Int J Radiat Oncol Biol Phys 90: 526-531.

55. Bitzer M, Topka H (1995) Progressive cerebral occlusive disease after radiation therapy. Stroke 26(1): 131-136.

56. Kondoh T, Morishita A, Kamei M, Okamura Y, Tamaki M, et al. (2003) Moyamoya syndrome after prophylactic cranial irradiation for acute lymphocytic leukemia. Pediatric Neurosurgery 39(5): 264-269.

57. Nishizawa S, Ryu H, Yokoyama T, Ninchoji T, Shimoyama I, et al. (1991) Post-irradiation vasculopathy of intracranial major arteries in childrenreport of two cases. Neurologia Medico-Chirurgica 31(6): 336-341.

58. Ishikawa N, Tajima C, Yofune N, Nishimura S, Kobayashi M (2006) Moyamoya syndrome after cranial irradiation for bone marrow transplantation in a patient with acute leukemia. Neuropediatrics 37(6): 364-366.

59. Veninga T, Langendijk HA, Slotman BJ, Rutten EH, van der Kogel AJ, et al. (2001) Reirradiation of primary brain tumours: survival, clinical response and prognostic factors. Radiother Oncol 59(2): 127-137.

60. Mark O’Beirn, Helen Benghiat, Sara Meade, Geoff Heyes, Vijay Sawlani, et al. (2018) The Expanding Role of Radiosurgery for Brain Metastases. Medicines (Basel) 5(3): 90
61. Aoyama H, Shirato H, Tago M (2006) Stereotactic radiosurgery plus whole-brain radiation therapy vs stereotactic radiosurgery alone for treatment of brain metastases: A randomized controlled trial. JAMA 295(21): 2483-2491.

62. Kocher M., Soffietti R., Abacioglu U (2011) Adjuvant whole-brain radiotherapy versus observation after radiosurgery or surgical resection of one to three cerebral metastases: Results of the EORTC 22952-26001 study. J Clin Oncol 29(2): 134-141.

63. Soffietti R, Kocher M, Abacioglu UM (2013) A European Organisation for Research and Treatment of Cancer phase III trial of adjuvant whole-brain radiotherapy versus observation in patients with one to three brain metastases from solid tumors after surgical resection or radiosurgery: Quality-of-life results. J Clin Oncol 31(1): 65-72.

64. Aoyama H, Tago M, Shirato H (2015) Japanese Radiation Oncology Study Group 99-1 (JROSG 99-1) Investigators. Stereotactic radiosurgery with or without whole-brain radiotherapy for brain metastases: Secondary analysis of the JROSG 99-1 randomized clinical trial. JAMA Oncol 1(4): 457-464.

65. Chang EL, Wefel JS, Hess KR (2009) Neurocognition in patients with brain metastases treated with radiosurgery or radiosurgery plus wholebrain irradiation: A randomised controlled trial. Lancet Oncol 10(11): 1037-1044.

66. Correa DD (2017) An update on cognitive functions in patients with brain tumors.

67. Gondi V, Hermann BP, Mehta MP, Tomé WA (2012) Hippocampal dosimetry predicts neurocognitive function impairment after fractionated stereotactic radiotherapy for benign or low-grade adult brain tumors. Radiat Oncol Biol 83(4): e487-e493.

68. Gondi V, Pugh SL, Tomé WA (2014) Preservation of memory with conformal avoidance of the hippocampal neural stem-cell compartment during whole-brain radiotherapy for brain metastases (RTOG 0933): A phase II multi-institutional trial. J Clin Oncol 32(34): 3810-3816.

69. www.bnos.org.uk

70. Grotzer M (2003) Current outcome predictors in childhood primitive neuroectodermal tumors. J Pediatric Neurology 1(2): 75-82.

71. Le QT, Weil MD, Wara WM, Lamborn KR, Prados MD, et al. (1997) Adult medulloblastoma: an analysis of survival and prognostic factors. The Cancer Journal from Scientific American 3(4): 238-245.

72. Herrlinger U, Steinbrecher A, Rieger J (2005) Adult medulloblastoma: prognostic factors and response to therapy at diagnosis and at relapse. J Neurol 252(3): 291-299.

73. Brandes AA, Palmisano V, Monfardini S (1999) Medulloblastoma in adults: clinical characteristics and treatment. Cancer Treat Rev 25(1): 3-12.

74. Skolyszewski J, Glinski B (1989) Results of postoperative irradiation of medulloblastoma in adults. International Journal of Radiation Oncology Biology Physics 16(2): 479-482.

75. Le Péchoux C, Dunant A, Senan S, Wolfson A, Quoix E, et al. (2009) Standard-dose versus higher-dose prophylactic cranial irradiation (PCI) in patients with limited-stage small-cell lung cancer in complete remission after chemotherapy and thoracic radiotherapy (PCI 99-01, EORTC 22003-08004, RTOG 0212, and IFCT 99-01): a randomised clinical trial. Lancet Oncol 10(5): 467-474.

76. Arriagada R, Le Chevalier T, Borie F (1995) Prophylactic cranial irradiation for patients with small-cell lung cancer in complete remission. Journal of the National Cancer Institute 87(3): 183-190.

77. Ghia A, Tomé WA, Thomas S (2007) Distribution of brain metastases in relation to the hippocampus: implications for neurocognitive functional 
preservation. International Journal of Radiation Oncology Biology Physics 68(4): 971-977.

78. Gutiérrez AN, Westerly DC, Tomé WA (2007) Whole brain radiotherapy with hippocampal avoidance and simultaneously integrated brain metastases boost: a planning study. International Journal of Radiation Oncology Biology Physics 69(2): 589-597.

79. Marsh JC, Herskovic AM, Gielda BT (2010) Intracranial metastatic disease spares the limbic circuit: a review of 697 metastatic lesions in 107 patients. International Journal of Radiation Oncology Biology Physics 76(2): 504-512.

80. Kier EL, Kim JH, Fulbright RK, Bronen RA (1997) Embryology of the human fetal hippocampus: Mr imaging, anatomy, and histology. American Journal of Neuroradiology 18(3): 525-532.

81. Roman DD, Sperduto PW (1995) Neuropsychological effects of cranial radiation: current knowledge and future directions. International Journal of Radiation Oncology Biology Physics 31(4): 983-998.

82. DeAngelis LM, Delattre J-Y, Posner JB (1989) Radiation-induced dementia in patients cured of brain metastases. Neurology 39(6): 789-796.

83. Li J, Bentzen SM, Li J, Renschler M, Mehta MP (2008) Relationship between neurocognitive function and quality of life after whole-brain radiotherapy in patients with brain metastasis. International Journal of Radiation Oncology Biology Physics 71(1): 64-70.

84. Palmer SL, Goloubeva O, Reddick WE (2001) Patterns of intellectual development among survivors of pediatric medulloblastoma: a longitudinal analysis. Journal of Clinical Oncology 19(8): 2302-2308.

85. Merchant TE, Kiehna EN, Li C, Shukla H, Sengupta S, et al. (2006) Modeling radiation dosimetry to predict cognitive outcomes in pediatric patients with CNS embryonal tumors including medulloblastoma. International Journal of Radiation Oncology Biology Physics 65(1): 210-221.

86. Duffner PK, Horowitz ME, Krischer JP, Friedman HS, Burger PC, et al. (1993) Postoperative chemotherapy and delayed radiation in children less than three years of age with malignant brain tumors. New England Journal of Medicine 328(24):1725-1731.

87. Rutkowski S, Bode U, Deinlein F, Ottensmeier H, Warmuth-Metz M, et al. (2005) Treatment of early childhood medulloblastoma by postoperative chemotherapy alone. New England Journal of Medicine 352(10): 978986.

88. Duffner PK (2004) Long-term effects of radiation therapy on cognitive and endocrine function in children with leukemia and brain tumors. Neurologist 10(6): 293-310.

89. Mulhern RK, Merchant TE, Gajjar A (2004) Late neurocognitive sequelae in survivors of brain tumours in childhood. Lancet Oncology 5(7): 399408.

90. Marsh J, Gielda B, Herskovic A (2010) Sparing of the limbic circuit and pituitary during whole brain radiation therapy: a dosimetric study using helical tomotherapy. Journal of Medical Imaging and Radiation Oncology 54(4): 375-382.

91. Eriksson PS, Perfilieva E, Björk-Eriksson T, Alborn AM, Nordborg C, et al. (1998) Neurogenesis in the adult human hippocampus. Nature Medicine 4(11): 1313-1317.

92. Reynolds BA, Weiss S (1992) Generation of neurons and astrocytes from isolated cells of the adult mammalian central nervous system. Science 255(5052): 1707-1710.
93. Taupin P, Gage FH (2002) Adult neurogenesis and neural stem cells of the central nervous system in mammals. Journal of Neuroscience Research 69(6): 745-749.

94. Doetsch F, Caille I, Lim DA, Garcia-Verdugo JM, Alvarez-Buylla A (1999) Subventricular zone astrocytes are neural stem cells in the adult mammalian brain. Cell 97(6): 703-716.

95. Morshead CM, Reynolds BA, Craig CG, McBurney MW, Staines WA, et al. (1994) Neural stem cells in the adult mammalian forebrain: a relatively quiescent subpopulation of subependymal cells. Neuron 13(5): 10711082.

96. Barani IJ, Cuttino LW, Benedict SH, Todor D, Bump EA, et al. (2007) Neural stem cell-preserving external-beam radiotherapy of central nervous system malignancies. International Journal of Radiation Oncology Biology Physics 68(4): 978-985.

97. Buglione M, Triggiani L, Grisanti S, et al. (2013) Retreatment of recurrent adult medulloblastoma with radiotherapy: a case report and review of the literature. Journal of Medical Case Reports 7: 64 .

98. Nieder C, Grosu AL, Andratschke NH, Molls M (2005) Proposal of human spinal cord reirradiation dose based on collection of data from 40 patients. Int J Radiat Oncol Biol Phys 61(3): 851-855.

99. Choi CY, Chang SD, Gibbs IC (2012) What is the optimal treatment of large brain metastases? An argument for a multidisciplinary approach. Int J Radiat Oncol Biol Phys 84(3): 688-693.

100. Angelov L, Mohammadi AM, Bennett EE, Abbassy M, Elson P (2017) Impact of 2-staged stereotactic radiosurgery for treatment of brain metastases $\geq 2 \mathrm{~cm}$. J Neurosurg 129(2): 366-382.

101. Han JH, Kim DG, Chung HT, Paek SH, Chul-Kee P, et al. (2012) Radiosurgery for large brain metastases. Int J Radiat Oncol Biol Phys 83(1): 113-120.

102. Lee CC, Yen CP, Xu Z, Schlesinger D, Sheehan J, et al. (2014) Large intracranial metastatic tumors treated by Gamma Knife surgery: outcomes and prognostic factors. J Neurosurg 120(1): 52-59.

103. Murai T, Ogino H, Manabe Y (2014) Fractionated stereotactic radiotherapy using CyberKnife for the treatment of large brain metastases: a dose escalation study. Clin Oncol 26(3): 151-158.

104. Navarria P, Pessina F, Cozzi L (2016) Hypo-fractionated stereotactic radiotherapy alone using volumetric modulated arc therapy for patients with single, large brain metastases unsuitable for surgical resection. Radiat Oncol 11: 76.

105. Sneed PK, Suh JH, Goetsch SJ, Sanghavi SN, Chappell R, et al. (2002) A multi-institutional review of radiosurgery alone vs. radiosurgery with whole brain radiotherapy as the initial management of brain metastases. Int J Radiat Oncol Biol Phys 53: 519-526.

106. Mehta MP, Tsao MN, Whelan TJ, Morris DE, Hayman JA, et al. (2005) The American Society for Therapeutic Radiology and Oncology (ASTRO) evidence-based review of the role of radiosurgery for brain metastases. Int J Radiat Oncol Biol Phys 63(1): 37-46.

107. Masucci GL (2018) Hypofractionated Radiation Therapy for Large Brain Metastases. Front Oncol 8: 379. 